J. Asiat. Soc. Bangladesh, Sci. 42(1): 41-48, June 2016

\title{
EFFECTS OF BOTANICALS AGAINST ANTHRACNOSE AND BLIGHT DISEASES OF HOUTTUYNIA CORDATA THUNB
}

\author{
TRISHA SAHA AND SHAMIM SHAMSI ${ }^{1}$ \\ Department of Botany, University of Dhaka, Dhaka-1000, Bangladesh
}

\begin{abstract}
Anthracnose and blight were recorded on Houttuynia cordata Thunb. during April 2013 to December 2013. The isolated fungi from the symptomatic plants were identified as Alterneria alternata (Fr.) Keissler and Colletotrichum gloeosporoides (Penz.) Sacc. Ethanol leaf extracts of five plants viz.,Azadirachta indica L., Citrus limon L., Datura metel L., Sennaalata L. and Tagetes erecta L.were evaluated against the pathogenic fungi A. alternata and C. gloeosporoides at 5\%, $10 \%$ and $20 \%$ concentrations in vitro. $A$. indica recorded as good inhibitor against the test fungi followed by C. limon, S. alata, $D$. metel and T.erecta. In vivo treatment also showed that A.indica is the most effective in controlling diseases at $10 \%$ concentration. The plants treated with $A$. indica were fresh and healthy up to one month of observation.
\end{abstract}

Key words: Anthracnose, Blight, Houttuynia cordata, Botanicals

\section{Introduction}

The plant Houttuynia cordata Thunb., the single species in the genus Houttuynia belonging to the family Saururaceae is a traditional medicinal herb. It is known as "Chameleon Plant" and its local name is "Aistya Gachh". This plant is mainly native to Japan, Korea, Southern China and Southeast Asia. It is widely distributed in the tropical Himalaya from Garwhal to Sikkim, Assam, Khasia Mountains. It mostly grows in hilly areas with providing moist and shady places. In Bangladesh it is found in Sylhet and Narail districts.

Houttuynia is herbaceous perennial plant which grows up to $50 \mathrm{~cm}$ tall. The leaves are simple, alternate, broadly ovate-cordate, 6.0 x 5.8. Flowers are white, bisexual and grow usually in summer (May-June). The plant grows well in moist to wet soil and even slightly submerged in water in partial or full sun (Ahmed et al. 2009).

The herb has a decayed, fishy smell to which its name refers, inspite of the fact it is eaten by the Chineseas as a salad. Its ethnobotanical uses considered for poisoned sores (furuncles), infectious skin diseases, piles, malaria, snakebite and other ailments. It is used as an antipyretic and detoxicant and is frequently used to treat pulmonary infections. It is antitumorous and is a special medicine for lung cancer (Smith and Stuart 1973\}.

Remarkable research findings are available on medicinal properties of the plant in abroad (Wang 1994, Dong et al. 1998, Zhu 1998 and Ahmed et al. 2009). But little information

\footnotetext{
${ }^{1}$ Corresponding author
} 
is available regarding the fungal diseases of the plant in home and abroad (Azad and Shamsi 2011and Zheng et al. 2011).Previously it was reported that symptoms appeared on leaves of H. cordatafrom September 2007 to November 2009 in Dangyang County, Hubei, China and the crop area affected estimated to be over 600 ha per year. Rhizome yield was reduced by $20 \%$ on average, with up to $70 \%$ yield losses in some fields during the autumn growing season (Zheng et al. 2011).So far there is no report available regarding the control of the diseases of $H$. cordata.Present research was undertaken to find out a suitable ecofriendly management of the diseases of this important herbal medicinal plant.

\section{Materials and Methods}

Leaves of H.cordata plants showing anthracnose and blight symptoms were collected from experimental field plots of Botanical Garden, Curzon Hall campus, Dhaka University, during April to December 2013.

The fungi were isolated from samples following the "Tissue Planting" method on PDA medium and "Blotter" method (CAB 1968).Identification of the isolates was determined following the standard literatures (Ellis 1971, 1976, Sutton1980, Ellis and Ellis 1998 and Barnett and Hunter 2000).

Pathogenicity test of the isolated fungi: All the isolated fungi were tested for their pathogenic potentiality following "Detached leaf technique”(Azad and Shamsi 2011) and "Spraying of spore suspension" method (Shamsi et al. 2003).The pathogenic fungi screened from "Detached leaf assay"were selected for net house experiment.Healthy plants of $H$. cordata were selected for pathogenicity test. The overall experiment was conducted in net house of Botanical Garden, Curzon Hall campus, Dhaka University. Plants were grown in 12 inch earthen pot containing sterilized soil for 6 weeks. Five plants were transplanted in each pot. Three replications were maintained for each treatment with five pots per replication. Test fungi were grown on PDA medium for 7-10 days. Spore suspension of each of the pathogenic fungus at the rate of $10^{4} \mathrm{spores} / \mathrm{ml}$ concentration was sprayed on healthy plants using hand sprayer. Inoculated plants were covered by perforated polythene bags to avoid contamination and to maintain humidity. Symptoms were recorded and fungi were re-isolated to fulfill Koch's postulate.

Plant extract used in the experiment and their preparation: Azadirachta indica, Citrus limon, Datura metel, Senna alata and Tageteserecta were selected for the experiment.Hundred gms of collected plant materials were washed in sterile distilled water. Then the plant materials were chopped into small pieces.Stock solution of an extract of each plant was individually prepared using sterile water and chopped leaf material $(1: 1 \mathrm{w} / \mathrm{v})$ in a clean blender. The mass of a plant part were squeezed through three folds of fine cloth. The supernatants were filtered through Whatman filter paper No.1 and the filtrate was collected in $250 \mathrm{ml}$ Erlenmeyer flasks. 5\%, 10\% and 20\% 
concentrations were prepared from stock solution (2014) following Shamsi et al. and evaluated against two pathogenic fungi following poison food techniques (Grover and Moore 1962).

Fifteen $\mathrm{ml}$ of autoclaved PDA medium supplemented with 5\%, 10\% and 20\% ethanol plant extracts were separately poured into Petri plates from lest tubes, allowed to cool and solidify. The Petri plates containing media devoid of the extract but with same amount of distilled water served as control. After complete solidification of the medium, $5 \mathrm{~mm}$ disc of seven day old culture of each test pathogen was inoculated in the centre of the Petri plates with solidified PDA medium. The plates were incubated at $25 \pm 2{ }^{\circ} \mathrm{C}$ for seven days.After incubation the colony diameter was measured in $\mathrm{mm}$ (Singh and Tripathi 1999). For each treatment three replications were maintained. The fungitoxicity of the extracts in terms of percentage inhibition of mycelial growth (I) was calculated using the formula: Percent inhibition = C - T / C X 100, where C = Average increase in mycelial growth in control plate and $\mathrm{T}=$ Average increase in mycelial growth in treatment plate.

Application of plant extracts in controlling anthracnose and blight of $H$. cordata: Houttuynia cordata was grown in 12 inch earthen pot containing sterilized soil for 6 weeks. Five plants were transplanted in each pot. Three replications were maintained for each treatment. Ethanol leaf extracts of five selected plants were screened in laboratory against test fungi. Among them A.indica showing complete inhibition of radial growth of the fungi at all the concentrations used were selected for controlling disease in net house experiment.Ethanol leaf extract of the plant at $10 \%$ concentration was sprayed on healthy plants by hand sprayer. Control plants were washed with distilled water. All the plants were covered by perforated polythene bags for 48 hours to avoid contamination. The experiment was conducted in net house of Botanical garden, Curzon Hall, Campus, DU. These pots were observed for one month in August 2013.

Measurement of disease severity: Disease severity were estimated by the following formula:

$$
\text { Severity }=\frac{\text { Sum of all Ratings }}{-----------------------~} \times 100
$$

For visual estimation of severity, 0-9 point scale was used for rating of all foliar diseases studied (PDI=McKinney's Index, Ghos et al. 2009).

No infection $-0,0-10 \%$ leaf area infected $-1,10-20 \%$ leaf area infected $-2,20-$ $30 \%$ leaf area infected $-3,30-40 \%$ leaf area infected $-4,40-50 \%$ leaf area infected $5,50-60 \%$ leaf area infected $-6,60-70 \%$ leaf area infected $-7,70-80 \%$ leaf area infected $-8,80-90 \%$ or more leaf area infected -9 .

\section{Results and Discussion}

Anthracnose and blight were recorded on H. cordata leaf during April to December 2013 (Plate 1). 
Seven fungal species were isolated from 18 examined samples of $H$. cordata belonging to 6 genera. The isolated 7 fungi namely Alterneria alternata, Aspergillus fumigatus, Aspergillus niger, Colletotrichum gloeosporioides, Curvularia lunata, Pestaliopsis guepiniand, Rhizopus stolonifer were tested for their pathogenic potentiality. The results revealed that $A$. alternata and $C$. gloeosporioides produced symptoms on $H$. cordata. Zheng et al. (2011) first reported leaf spot of $H$. cordata caused by A. alternata from China.
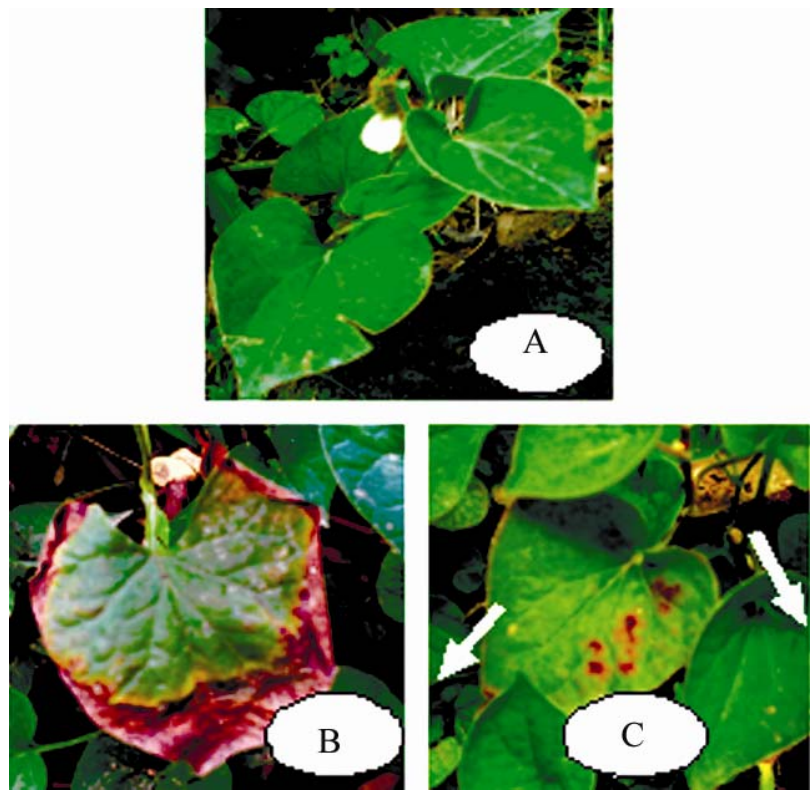

Plate 1. Houttuynia cordata: A. Healthy plants. B. Plants showing anthracnose and C. blight symptoms.

Azad and Shamsi (2011) recorded two types of symptoms (Anthraci sse and leaf spot) on $H$. cordata and 17 species of fungi in their exper:ment. Among these 3 fungal species of Colletotrichum were found to be pathogenic tc the plant. Result of present study slightly differs from previous result reported by Azad and Shamsi (2011).

Considerable research has been carried out and scientists successfully controlled plant pathogenic fungi with plant extract. These are safe and suitable biological control agents against fungal plant pathogens (Misher and Das 1992, Singh and Tripathi 1999, Varma and Dubey 1999 and Sharmin and Shamsi 2013).Common and locally available plants with antimicrobial activity viz., A. indica, C. limon, D. metel, S. alata, and T.erecta were selected in this experiment. Ethanol leaf extract of the plants at $20 \%, 10 \%$ and $5 \%$ concentrations were evaluated on radial growth of the two pathogenic fungi A. alternata and $C$. gloeosporioides of $H$. cordata. Results of the experiment are presented in Figs. 1 and 2. 
Effect of plant extracts on radial growth of Alterneria alternata in vitro:Ethanol extracts of five angiospermic plants were used in this experiment. Among the selected plants A. indica showed $100 \%$ inhibition of radial growth of the fungus at all concentrations used. Exclusively at 20\% concentration other plant extracts showed 100\% inhibition of radial growth of test fungus. Citrus limon and S. alataalso showed 100\% inhibition of radial growth of the fungus at $10 \%$ concentration.. Whereas D. metel and T. erecta were capable of $68.57 \%$ and $58.18 \%$ radial growth inhibition of test fungus at the same concentration. Citrus limon, T. erecta, S. alata and D.metel showed 57.89\%, 50\%, 42.42\% and $40 \%$ inhibition of radialgrowth of the test fungus at $5 \%$ concentration (Fig.1).

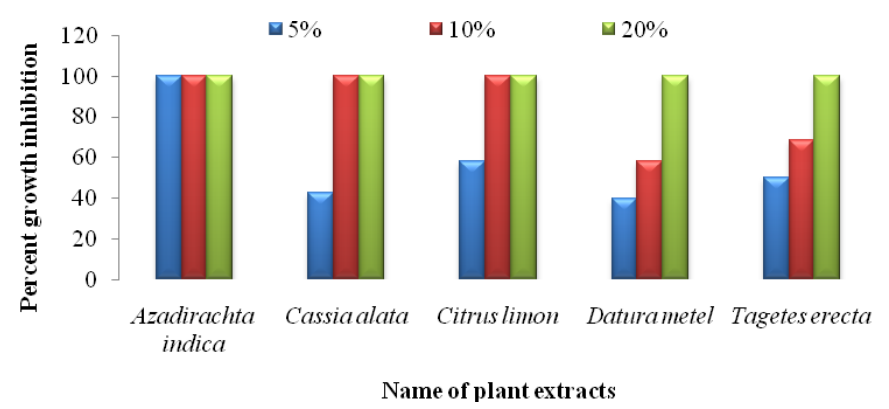

Fig. 1. Effect of plant extract on the radial growth of Alternaria alternata at different concentrations.

Effect of plant extracts against radial growth of Colletotrichum gloeosporioides in vitro: Azadirachta indica showed $100 \%$ inhibition of radial growth of test fungus at all concentrations used. Similar result was observed in case of A. alternata. Rest of the plant extracts showed $100 \%$ inhibition of radial growth of the fungus at $20 \%$ and $10 \%$ concentrations, respectively. Datura metel,C. limon, T. erecta and S. alata were capable of $76.39 \%, 69.23 \%, 60.38 \%$, and $36.67 \%$ inhibition of radial growth of the fungus at $5 \%$ concentration (Fig. 2). Efficacy gradients indicates that $A$. indica and $C$. limon were the best inhibiting agent against the radial growth of A. alternata and $C$. gloeosporioides the causal agents of blight and anthracnose of $H$. cordata.

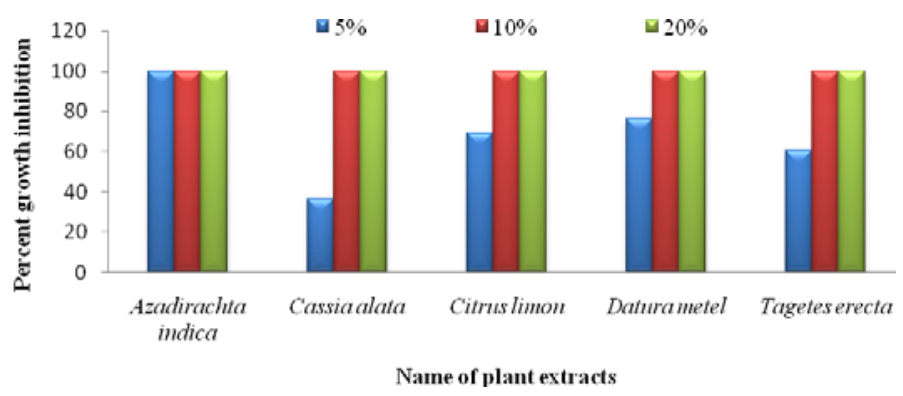

Fig. 2. Effect of plant extracts on the radial growth of Colletotrichum gloeosporioides at different concentrations. 
Effectof plant extracts in controlling diseases of Houttuyniacordata: Extract of Azadirachta indica at $10 \%$ concentration was sprayed over the plants in net house. After one month of application, the treated plants did not show infection. Moreover, plant height and leaf size increased more than control plants. On the other hand control plants gradually showed symptoms with the application of fungi. Plants became shorter compared to treated plants. Disease severity was recorded on control (untreated plants) at (0-9) DS scale during development of symptom. Highest disease severity 8 was recorded at the end of $4^{\text {th }}$ week followed by DS 5 at the end of $3^{\text {rd }}$ week, DS 2 was recorded at the beginning of $2^{\text {nd }}$ week.At the end of first week plants were apparently healthy.Up to one month of observation treated plants remained symptomless (Tables 1, 2 and Plate 2).
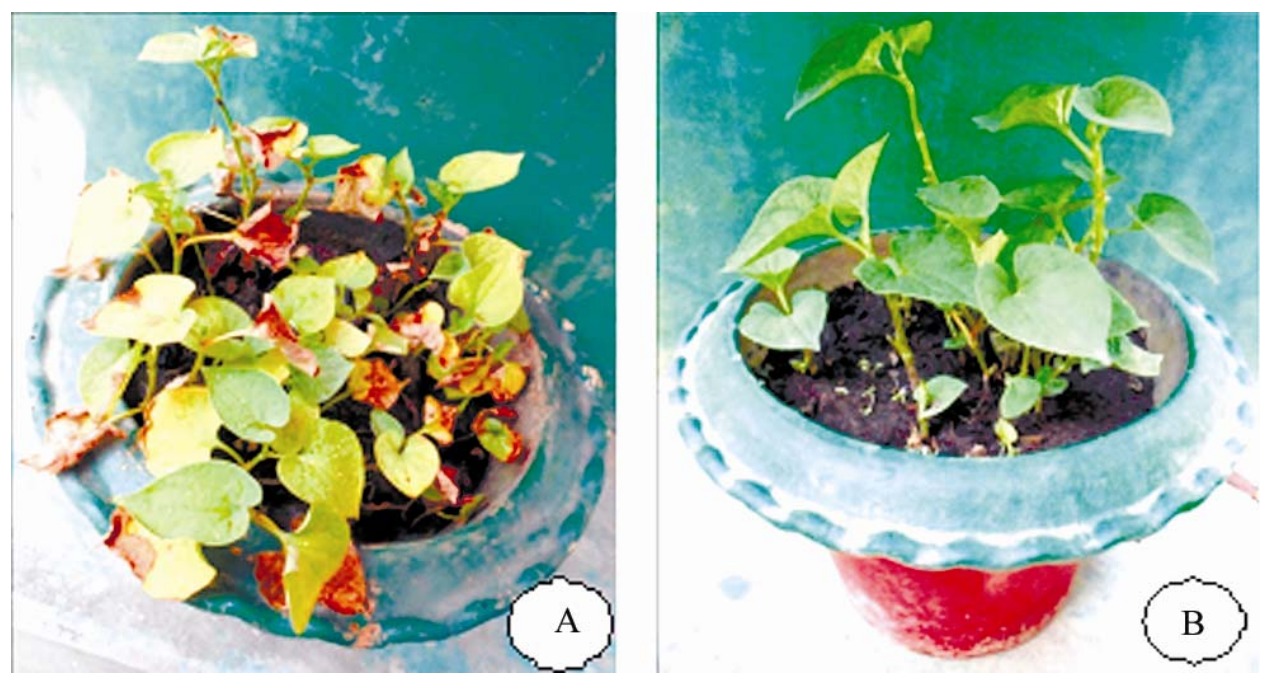

Plate 2. Houttuynia cordata: A. Infected plants (Control); B: Plants treated with Azadirachta indica at $10 \%$ concentration.

Table 1. Effect of A. indica extract on plant height and leaf size of $H$. cordata.

\begin{tabular}{|c|c|c|c|c|c|}
\hline \multicolumn{3}{|c|}{ Control plants } & \multicolumn{3}{|c|}{ A. indica treated plants } \\
\hline Plant height & leaf length & width (cm) & plant height & leaf length & width $(\mathrm{cm})$ \\
\hline 16.5 & 5.4 & 3.7 & 21.0 & 6.0 & 4.5 \\
\hline
\end{tabular}

Mean calculated from 25 plants examined. 
Table 2. Disease severity recorded on untreated control plants of $H$. cordata in August 2013.

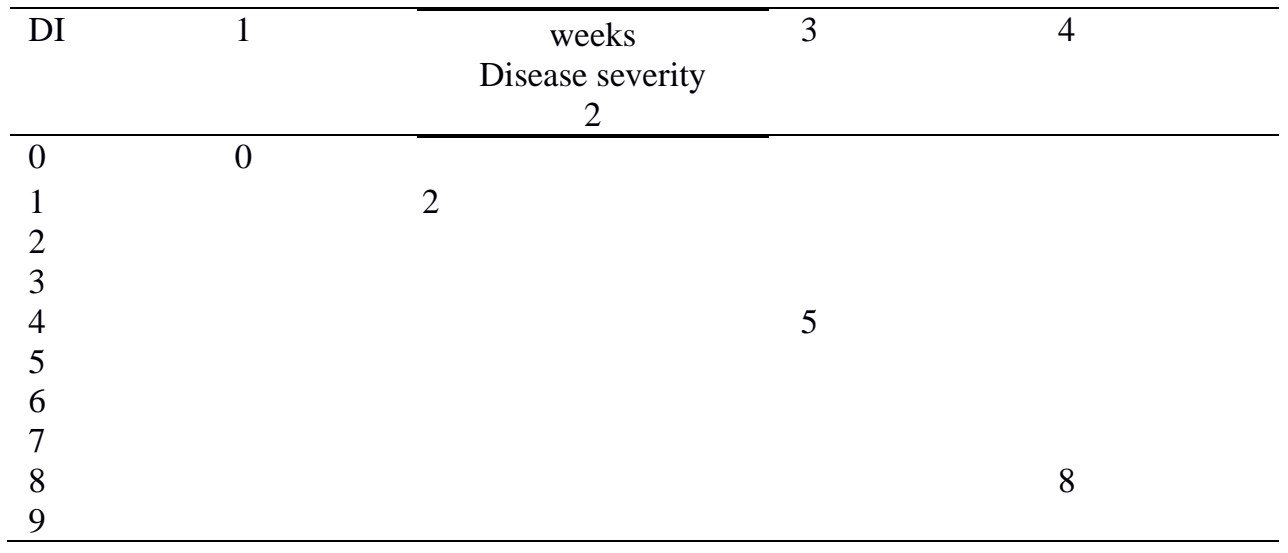

Mean calculated from 25 plants examined.

Exploitation of naturally available chemicals from plants, which retards the reproduction of undesirable microorganisms, would be a more realistic and ecologically sound method for plant protection and will have a prominent role in the development of future commercial and safe fungicide for crop protection strategies, with special reference to control the fungal plant diseases.Present research is a new addition in the field of Plant Pathology.

\section{Acknowledgements}

The authors express their gratitude and thanks to Ministry of Science and Technology, Govt. of the People's Republic of Bangladesh for the financial support in the form of NST fellowship to the first author as M.S. Scholarship. The authors are also grateful to Professor Abul Bashar, Chairman, Department of Botany, University of Dhaka for his constant inspiration and cooperation during the course of the study.

\section{References}

Ahmed, Z.U., M.A. Hassan, Z.N.T. Begum, M. Khondker, S.M.H. Kabir, A.M.Ahmed and A.T.A. Ahmed(eds.) 2009. Encyclopedeia of Flora and Fauna of Bangladesh. Vol.10. Angiosperm: Dicotyledons (Ranunculaceae- Zygophyllaceae). Asiatic Soc. Bangladesh, Dhaka. pp. 227.

Azad, R. and S. Shamsi . 2011. Identification and pathogenic potentiality of fungi associated with Houttuynia cordata Thunb. Dhaka Univ. J. Biol. Sci.20 (2): 131-138.

Barnett, H. L. and B. B. Hunter. 2000. Illustrated Genera of Imperfect Fungi. (4th edn.), Burgessbub. Co. Minneapolis. pp. 218.

CAB (Commonwealth Agricultural Bureau). 1968. Plant Pathologist's Pocket Book. The Commonwealth Mycological Institute. Kew. Surrey. England. pp. 267.

Dong, K.S., X.Q. Wang and Y.F. Dong. 1998. Xian Dai Lin Chuang Zhong YaoXue [Contemporary Clinical Chinese Materia Medioca]. Beijing: Zhong Guo Zhong Yi Yao Press.

Ellis, M.B. 1971. Dematiaceous Hyphomycetes. Commonwealth Mycological Institute,England. pp. 608. 
Ellis, M.B. 1976. More Dematiaceous Hyphomycetes. Commonwealth Mycological Institute, England.pp. 507.

Ellis, M. and J.P. Ellis. 1997. Micro fungi on Land Plants. An Identification Handbook. The Richmond Publishing Company Ltd. pp. 868.

Ghosh, P.P., D. Mandal, S. Laha and M.K.Dasgupta. 2009. Dynamics and severity model in managing fungal diseases. The Journal of Pl. Ptotec. Sci.1(1):55-59.

Grover, R.K., J.D. Moore .1962.Taxicometric studies of fungicides against brown rot organism Sclerotinia fructicola and S. laxa. Phytopathology.52:876-880.

Misher and T. Das. 1992. Efficacy of plant extracts in plant disease management. Agricultural Sciences 3: 425-433.

Sharmin, S. and S., Shamsi. 2013. In-vitro control of five pathogenic fungi isolated from groundnut (Arachis hypogaea L.). J. Asiatic. Soc. Bangladesh. Sci. 39(1) : 27-33.

Shamsi, S., A. K. M. Nowsher A. Khan, A.K.M. Shahjahan and S. A. Miah. 2003. Fungal species associated with sheaths and grains of sheath rot affected rice varieties from Bangladesh. Bangladesh J. Bot. 32(1): 17-22.

Shamsi, S. P. Chowdhury and T. Sultana. 2014. In vitro control of causal agents of anthracnose of Seena alata L. - a herbal medicinal plant in Bangladesh. MAPRJ. 2(3):37-43.

Singh, J. and N.N. Tripathi.1999. Inhibition of storage fungi of blackgram (Vigna mungo L.) by some essential oils. Flavour and Fragrance Journal. 14: 1-4.

Smith, F.P. and G.A. Stuart. 1973. Chinese Medicinal Herbs. San Francisco: Georgetown Press.

Sutton, B.C .1980. The Coelomycetes. Fungi Imperfect with Pycnidia Acervuli and Stromata. Commonwealth Mycological Institute, Kew Surrey, England. pp. 696.

Varma, J. and N.K. Dubey. 1999. Prospectives of botanical and microbial products as pesticides of Tomorrow. Curr. Sci.76: 172-179.

Wang, J. H. (Ed.) 1994. Xin Bian Chang Young Zhong Yao shou Ce [Manual of Commonl Used Chinese Medicinal Herbs]. Beijing: Jin Dun Press.

Zheng, L., R. Lv, Q. Li, and J. Huang. 2011.First Report of Leaf Spot of Houttuynia cordata Causedby Alternaria alternata in China. Plant Disease. 95 (3): 359.

Zhu, Y. 1998. Chinese Materia Medica Chemistry, Pharmacology andApplications. Amsterdam: Harwood Academic Publishers.

(Revised copy received on 27-06-2016) 